\title{
Novel biologic therapies for thymic epithelial tumors
}

\author{
Yuanbin Chen, Helen Gharwan and Anish Thomas* \\ Thoracic and Gastrointestinal Oncology Branch, National Cancer Institute, National Institutes of Health, Bethesda, MD, USA \\ *Correspondence: anish.thomas@nih.gov \\ Edited and reviewed by: \\ Giuseppe Giaccone, Georgetown University, USA
}

Keywords: thymic epithelial tumors, thymoma, thymic carcinoma, cixutumumab, sunitinib, belinostat

\section{A commentary on}

Cixutumumab for patients with recurrent or refractory advanced thymic epithelial tumours: a multicentre, openlabel, phase 2 trial

by Rajan A, Carter CA, Berman A, Cao L, Kelly RJ, Thomas A, et al. (2014). Lancet Oncol 15:191-200. doi:10.1016/ S1470-2045(13)70596-5

Thymic epithelial tumors (TETs) are comprised of a spectrum of histologically distinct tumors that also exhibit differences at the molecular level (1). Surgery is the mainstay of treatment but locally advanced and metastatic TETs can be inoperable and are associated with worse survival (2). Although multi-agent chemotherapy is associated with objective response rates (ORR) of $50-90 \%$ in the front-line setting [e.g., cisplatin, doxorubicin, and cyclophosphamide (CAP) (3), doxorubicin, cisplatin, vincristine, and cyclophosphamide (ADOC) (4)], no standard systemic treatments exist for relapsed or refractory TETs. Several biological agents have been evaluated in TETs in small phase II trials as illustrated in Table 1.

\section{SOMATOSTATIN ANALOGS}

Somatostatin receptors are expressed in TETs and can be detected by octreotide scan (17). Palmieri et al. first showed efficacy of octreotide/lanreotide with or without prednisone in TETs (5). In another larger phase II trial, 38 patients with octreotide scan-positive TETs were treated with octreotide for 2 months. Responding patients continued to receive octreotide alone whereas patients with stable disease received additional prednisone for a maximum of 10 additional months. Two complete $(5.3 \%)$ and 10 partial responses $(25 \%)$ were observed in patients with thymoma, but no response was seen in thymic carcinoma (6).

\section{HISTONE DEACETYLASE INHIBITORS}

Histone deacetylases (HDACs) regulate gene expression through chromosome remodeling. Belinostat is a HDAC inhibitor that has been evaluated in a phase II trial in patients with advanced TETs after failure of platinum-containing chemotherapy (7). Among 25 patients with thymoma, and 16 with thymic carcinoma, two patients with thymoma achieved partial responses. No responses were seen among patients with thymic carcinoma. Median time to progression in patients with thymoma and thymic carcinoma was 11.4 and 2.7 months, respectively. Median survival was not reached in patients with thymoma and it was 12.4 months in patients with thymic carcinoma. Belinostat has also been evaluated with CAP in the front-line setting in a phase I/II trial. The overall response rate was $71 \%$ in thymoma and $33 \%$ in thymic carcinoma (8).

\section{INSULIN-LIKE GROWTH FACTOR RECEPTOR INHIBITORS}

Thymic epithelial tumors express insulinlike growth factor-1 receptor (IGF-1R), particularly recurrent or advanced tumors and those with aggressive histological subtypes (18). Cixutumumab, a fully human IgG1 monoclonal antibody that binds to IGF-1R with high affinity and induces internalization and degradation of the receptor, has been evaluated in a phase II trial of 37 patients with thymoma and 12 patients with thymic carcinoma, who had progressive disease after prior platinum-containing chemotherapy (9). Patients received cixutumumab at a dose of $20 \mathrm{mg} / \mathrm{kg}$ intravenously every 3 weeks until disease progression or development of intolerable toxicities. With a median follow up of 24 months, 5 of
37 thymoma patients achieved a partial response (ORR 14\%). The median time to progression was 9.9 months and median survival was 27.5 months. In contrast, no responses were seen in patients with thymic carcinoma and the median time to progression and overall survival were 1.7 and 8.4 months, respectively. A significant increase in IFN $\gamma$-expressing $\mathrm{CD} 4+\mathrm{T}$ cells and reduction in circulating endothelial progenitor cells (CEPs) were observed with treatment among responders. The potential predictive value of these biomarkers is under further investigation.

\section{MULTIKINASE INHIBITORS}

Multiple case reports have described responses to the multikinase inhibitors, sorafenib (19) and sunitinib (20) in patients with previously treated thymic carcinoma. To confirm the activity of sunitinib in previously treated TETs, 22 patients with thymoma and 16 with thymic carcinoma with progressive disease following at least one platinum-based chemotherapy regimen were enrolled in a phase II study. Sunitinib was administered orally at a dose of $50 \mathrm{mg}$ once daily in 6-week cycles ( 4 weeks on 2 weeks off). In 19 evaluable patients with thymic carcinoma and 16 evaluable patients with thymoma, the ORR was 16 and $6 \%$, respectively, and PFS was 6.2 and 5.5 months, respectively. Adverse events included cytopenia, fatigue, mucositis, hypertension, and reversible decline in left ventricular ejection. Additionally, $10(53 \%)$ patients with thymic carcinoma had tumor shrinkage between 10 and $29 \%(12)$.

\section{EPIDERMAL GROWTH FACTOR RECEPTOR, KIT AND SrC INHIBITORS}

Despites preclinical data demonstrating overexpression of epidermal growth factor receptor (EGFR) (21) and KIT (22) and 
Table 1 | Published biological therapies in TETs.

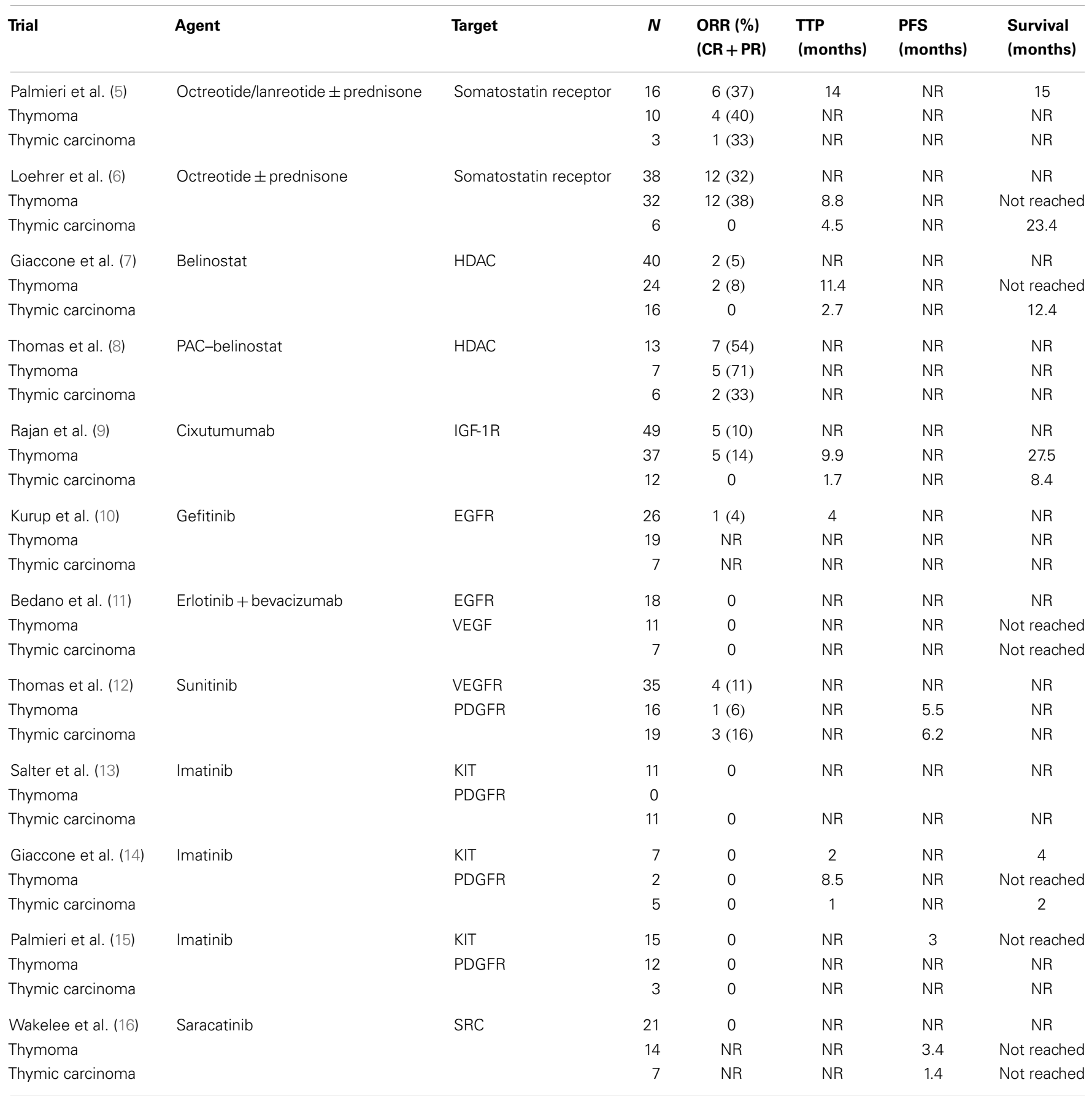

NR, not reported.

Src Kinase (23) in TETs, very low objective responses were observed in phase II studies evaluating these agents. A study using EGFR inhibitor, Gefitinib, yields only one response in 26 patients (10) while another study using Erlotinib plus Bevacizumab showed no response (11). Three trials evaluating KIT inhibitor Imatinib in TETs (13-15) showed zero objective response. It is notable that although most tumors on these trials overexpressed KIT, no sensitizing mutation was found. Src inhibitor Saracatinib also failed to yield any objective response in a TET trial (16). For more details on these studies, see Table 1.

\section{ONGOING TRIALS OF TARGETED} THERAPIES IN TETS

Milciclib, an inhibitor of cyclindependent kinase 2/cyclin A complex and tropomyosin receptor kinase A (TrkA) is being evaluated in two phase II studies in patients with recurrent B3 thymoma and thymic 
carcinoma (NCT01011439 and NCT 01301391).

A phase II study is evaluating the role of the mammalian target of rapamycin (mTOR) inhibitor, everolimus in patients with TETs previously treated with chemotherapy. (NCT02049047).

\section{CONCLUSION}

In conclusion, although the presence of targetable mutations detected by current techniques of molecular profiling is low, whole genome and exome sequencing has the potential to uncover novel biological targets. Although many trials of targeted agents have yielded disappointing results, the unprecedented activity of sunitinib in thymic carcinoma and the disease stabilizing effect of cixutumumab in thymoma provides an impetus to continue to explore the role of novel biological agents in TETs.

\section{REFERENCES}

1. Girard N, Shen R, Guo T, Zakowski MF, Heguy A, Riely GJ, et al. Comprehensive genomic analysis reveals clinically relevant molecular distinctions between thymic carcinomas and thymomas. Clin Cancer Res (2009) 15:6790-9. doi:10.1158/10780432.CCR-09-0644

2. Kondo K. Optimal therapy for thymoma. J Med Invest (2008) 55:17-28. doi:10.2152/jmi.55.17

3. Loehrer PJ Sr, Kim K, Aisner SC, Livingston R, Einhorn LH, Johnson D, et al. Cisplatin plus doxorubicin plus cyclophosphamide in metastatic or recurrent thymoma: final results of an intergroup trial. The Eastern Cooperative Oncology Group, Southwest Oncology Group, and Southeastern Cancer Study Group. J Clin Oncol (1994) 12:1164-8.

4. Fornasiero A, Daniele O, Ghiotto C, Piazza M, Fiore-Donati L, Calabro F, et al. Chemotherapy for invasive thymoma. A 13-year experience. Cancer (1991) 68:30-3. doi:10.1002/1097-0142(19910701)68:1<30::AIDCNCR2820680106>3.0.CO;2-4

5. Palmieri G, Montella L, Martignetti A, Muto P, Di Vizio D, De Chiara A, et al. Somatostatin analogs and prednisone in advanced refractory thymic tumors. Cancer (2002) 94:1414-20. doi:10.1002/ cncr. 10374

6. Loehrer PJ Sr, Wang W, Johnson DH, Aisner SC, Ettinger DS. Octreotide alone or with prednisone in patients with advanced thymoma and thymic carcinoma: an Eastern Cooperative Oncology Group Phase II Trial. J Clin Oncol (2004) 22:293-9. doi:10.1200/JCO.2004.02.047

7. Giaccone G, Rajan A, Berman A, Kelly RJ, Szabo E, Lopez-Chavez A, et al. Phase II study of belinostat in patients with recurrent or refractory advanced thymic epithelial tumors. J Clin Oncol (2011) 29:2052-9. doi:10.1200/JCO.2010.32.4467

8. Thomas A, Rajan A, Khozin S, Szabo E, Carter CA, Guha U, et al. A phase (Ph) I/II study of belinostat (Bel) in combination with cisplatin, doxorubicin, and cyclophosphamide (PAC) in the firstline treatment of advanced or recurrent thymic malignancies. J Clin Oncol (2012) 30:7103.

9. Rajan A, Carter CA, Berman A, Cao L, Kelly RJ, Thomas A, et al. Cixutumumab for patients with recurrent or refractory advanced thymic epithelial tumours: a multicentre, open-label, phase 2 trial. Lancet Oncol (2014) 15:191-200. doi:10. 1016/S1470-2045(13)70596-5

10. Kurup A, Burns M, Dropcho S, Pao W, Loehrer PJ. Phase II study of gefitinib treatment in advanced thymic malignancies. J Clin Oncol (2005) 23:7068-9.

11. Bedano PM, Perkins S, Burns M, Kessler K, Nelson $\mathrm{R}$, Schneider BP, et al. A phase II trial of erlotinib plus bevacizumab in patients with recurrent thymoma or thymic carcinoma. J Clin Oncol (2008) 26:19087.

12. Thomas A, Rajan A, Berman A, Scepura B, Brzezniak $C$, Carter CA, et al. Clinical activity of sunitinib in patients with thymic carcinoma. J Thorac Oncol (2013) 8:S267-8.

13. Salter JT, Lewis D, Yiannoutsos C, Loehrer PJ, Risley L, Chiorean EG. Imatinib for the treatment of thymic carcinoma. J Clin Oncol (2008) 26:8116.

14. Giaccone G, Rajan A, Ruijter R, Smit E, Van Groeningen C, Hogendoorn PC. Imatinib mesylate in patients with WHO B3 thymomas and thymic carcinomas. J Thorac Oncol (2009) 4:1270-3. doi: 10.1097/JTO.0b013e3181b6be57

15. Palmieri G, Marino M, Buonerba C, Federico P, Conti S, Milella $\mathrm{M}$, et al. Imatinib mesylate in thymic epithelial malignancies. Cancer Chemother Pharmacol (2012) 69:309-15. doi:10.1007/s00280011-1690-0

16. Wakelee HA, Gubens MA, Burns M, Barbeau SL, Perkins S, Pedo-Salcedo MGS, et al. A phase II study of saracatinib (AZD0530), a Src inhibitor, administered orally daily to patients with advanced thymic malignancies. Chicago Multidisciplinary Symposium in Thoracic Oncology, Poster 152. Chicago (2010).

17. Lastoria S, Vergara E, Palmieri G, Acampa W, Varrella P, Caraco C, et al. In vivo detection of malignant thymic masses by indium-111DTPA-D-Phe1-octreotide scintigraphy. J Nucl Med (1998) 39:634-9.

18. Zucali PA, Petrini I, Lorenzi E, Merino M, Cao L, Di Tommaso L, et al. Insulin-like growth factor-1 receptor and phosphorylated AKT-serine 473 expression in 132 resected thymomas and thymic carcinomas. Cancer (2010) 116:4686-95. doi:10.1002/cncr.25367

19. Neuhaus T, Luyken J. Long lasting efficacy of sorafenib in a heavily pretreated patient with thymic carcinoma. Target Oncol (2012) 7:247-51. doi:10.1007/s11523-012-0235-8

20. Strobel P, Bargou R, Wolff A, Spitzer D, Manegold C, Dimitrakopoulou-Strauss A, et al. Sunitinib in metastatic thymic carcinomas: laboratory findings and initial clinical experience. Br J Cancer (2010) 103:196-200. doi:10.1038/sj.bjc.6605740

21. Henley JD, Koukoulis GK, Loehrer PJ Sr. Epidermal growth factor receptor expression in invasive thymoma. J Cancer Res Clin Oncol (2002) 128:167-70. doi:10.1007/s00432-001-0319-9

22. Pan CC, Chen PC, Chiang H. KIT (CD117) is frequently overexpressed in thymic carcinomas but is absent in thymomas. J Pathol (2004) 202:375-81. doi:10.1002/path.1514

23. Khoury T, Arshad A, Bogner P, Ramnath N, Zhang $\mathrm{S}$, Chandrasekhar R, et al. Apoptosis-related (survivin, Bcl-2), tumor suppressor gene (p53), proliferation (Ki-67), and non-receptor tyrosine kinase (Src) markers expression and correlation with clinicopathologic variables in 60 thymic neoplasms. Chest (2009) 136:220-8. doi:10.1378/chest.082482

Conflict of Interest Statement: The authors declare that the research was conducted in the absence of any commercial or financial relationships that could be construed as a potential conflict of interest.

Received: 12 April 2014; accepted: 25 April 2014; published online: 07 May 2014.

Citation: Chen Y, Gharwan H and Thomas A (2014) Novel biologic therapies for thymic epithelial tumors. Front. Oncol. 4:103. doi: 10.3389/fonc.2014.00103 This article was submitted to Thoracic Oncology, a section of the journal Frontiers in Oncology.

Copyright (c) 2014 Chen, Gharwan and Thomas. This is an open-access article distributed under the terms of the Creative Commons Attribution License (CC BY). The use, distribution or reproduction in other forums is permitted, provided the original author(s) or licensor are credited and that the original publication in this journal is cited, in accordance with accepted academic practice. No use, distribution or reproduction is permitted which does not comply with these terms. 